\title{
Assessing Cortisol Production in Preterm Infants: Do Not Dispose of the Nappies
}

\author{
MATTHIAS HECKMANN, MICHAELA F. HARTMANN, BIRGIT KAMPSCHULTE, HEIKE GACK, \\ ROLF-HASSO BÖDEKER, LUDWIG GORTNER, AND STEFAN A. WUDY \\ Department of General Pediatrics and Neonatology [M.H., B.K., H.G., L.G., S.A.W.], Steroid Research \\ Unit [M.F.H., S.A.W.], Center of Child and Adolescent Medicine, Justus Liebig University, 35392 Giessen, \\ Germany, Institute of Medical Statistics [R.-H.B.], Justus Liebig University, 35392 Giessen, Germany
}

\begin{abstract}
The aim of this study was to develop a practical approach allowing a reliable and noninvasive assessment of cortisol production rates in premature infants. To measure daily urinary excretion rates of glucocorticoids, we developed a procedure using a hydraulic compression method to collect urine from cellulose nappies (diapers). Glucocorticoid metabolites were profiled by quantitative gas chromatography-mass spectrometry. Recovery of steroids after the process of hydraulic extraction from the nappy was approximately $100 \%$. Consecutively, urinary excretion rates of glucocorticoids could be determined in nine healthy preterm infants. The median urinary excretion rate of glucocorticoids increased significantly during the first $5 \mathrm{~d}$ of life and remained between $566 \mu \mathrm{g} / \mathrm{kg} / \mathrm{d}$ at $\mathrm{d} 5$ and $302 \mu \mathrm{g} / \mathrm{kg} / \mathrm{d}$ at 4 wk of age. However, this increase of urinary excretion rates of glucocorticoids in the first days of life was no longer significant when corrected for creatinine excretion. When calculated per
\end{abstract}

\section{ABSTRACT}

square meter body surface area, the median urinary excretion rates of glucocorticoids were $5.1,4.2,4.1$, and $3.7 \mathrm{mg} / \mathrm{m}^{2} / \mathrm{d}$ on $\mathrm{d}$ 5 , and at wk, 2, 3, and 4, respectively. Urinary excretion rates of glucocorticoids constitute approximately $70 \%$ of the natural cortisol production rate as determined by stable isotope dilution technique in older children. Additionally, low cortisol production was detected in two of five preterm infants with arterial hypotension requiring treatment with catecholamines. In conclusion, 24-h urine collection using disposable nappies in combination with gas chromatography-mass spectrometry steroid profiling proved to be a reliable, noninvasive, nonstressful procedure to assess cortisol production and metabolism in premature infants. (Pediatr Res 57: 412-418, 2005)

\section{Abbreviation}

GC-MS, gas chromatography-mass spectrometry
The important question, whether early adrenal insufficiency-possibly associated with increased pulmonary and circulatory morbidity-might be present in premature babies, has not yet been answered (1-3). Studies addressing this problem have been based on single plasma cortisol determinations by immunoassays. However, a single plasma cortisol concentration does not present a timely integral parameter and therefore does not allow assessment of the level of the cortisol production rate. Furthermore, steroid determinations by immunoassays can be associated with severe problems arising from cross-reactivity of steroids, especially in premature infants. This is due to the peculiarity of fetal and neonatal steroid metabolism: large amounts of potentially cross-reactive steroid sulfates retaining a $3 \beta$-hydroxy-5-ene structure are produced in the unique fetal zone of the adrenals (4). As a result, no

Received January 5, 2004; accepted August 16, 2004.

Correspondence: Matthias Heckmann, M.D., Department of General Pediatrics and Neonatology, Justus Liebig University, 35385 Giessen, Germany; e-mail Matthias.Heckmann@paediat.med.uni-giessen.de

Supported by a grant (HE 3557/1-1) of the Deutsche Forschungsgemeinschaft to M.H. and S.A.W.

DOI: 10.1203/01.PDR.0000153947.51642.C1 commercially available cortisol immunoassays have been developed that are appropriate for use in measuring steroids in plasma from premature infants or neonates.

A suitable scientific method allowing assessment of cortisol production rates in premature infants is still lacking. Such a procedure should ideally comprise measurement of the correct metabolites of glucocorticoid metabolism and should, for ethical reasons, be as noninvasive and gentle as possible with respect to the fragile premature infant.

Steroid determination in 24-h urinary specimens enables noninvasive assessment of hormonal production rates $(5,6)$. However, such an approach primarily requires a reliable method of collecting 24-h urinary specimens, a challenging task with regard to premature babies. A second hurdle consists in the premature baby's metabolism of cortisol, which is very different from the metabolism during the later periods of life. In particular, highly polar metabolites bearing additional hydroxyl groups at positions $1 \beta$ and $6 \alpha$ are produced. Furthermore, the high activity of $11 \beta$-hydroxysteroid dehydrogenase in many tissues of the fetus and neonate lead to a dominance of 11 -keto over $11 \beta$-hydroxy compounds $(7,8)$. A third hindrance 


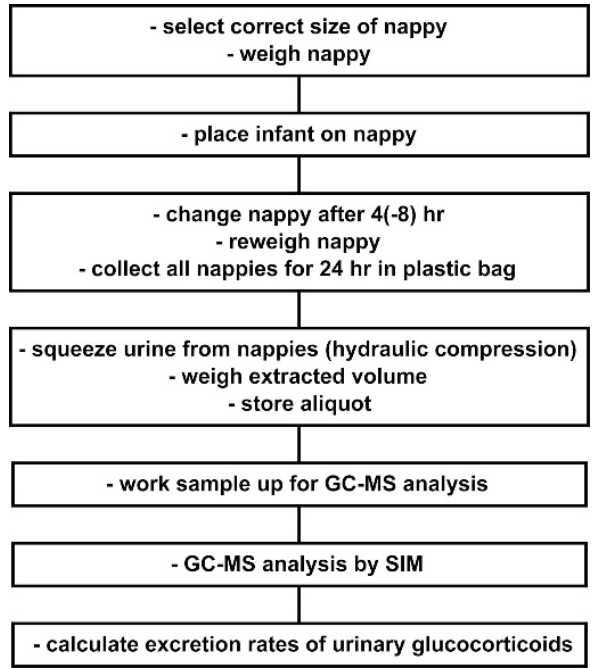

Figure 1. Assessment of glucocorticoid excretion rates in premature infants: flowchart of the procedure.

is the choice of the correct analytical method. Apart from the problem arising from cross-reactivity, there is no commercially available immunoassay for measuring these typical neonatal steroids.

The aim of this study was to develop a practical approach allowing reliable and noninvasive assessment of cortisol production rates in premature infants. To measure urinary excretion rates of glucocorticoids, we developed a special method for careful collection of 24-h urinary specimens in premature infants. To circumvent analytical problems arising from immunoassay detection, we chose the highly specific and nonselective analytical technique of GC-MS for profiling of urinary glucocorticoid metabolites in premature infants.

\section{METHODS}

The procedure of assessment of urinary excretion rates of glucocorticoids in premature infants is depicted in Figure 1.

Urine collection procedure. Urine was collected for $24 \mathrm{~h}$ using disposable nappies (diapers) $(9,10)$. We used two sizes of disposable nappies (Pampers, Procter \& Gamble, Schwalbach, Germany). The small size derived from a serial production, which was used for infants weighing $<2.3 \mathrm{~kg}$ (Pampers P). For infants weighing 2.3-6 kg, medium-sized nappies were manufactured exclusively for us. The nappies were composed of pure cellulose.
THE $6 \mathrm{a}-\mathrm{OH}-\mathrm{THE} / 1 \mathrm{~b}-\mathrm{OH}-\mathrm{THE}$ Abundance lon 578.40 (578.10 to 579.Abundance lon 666.40 (666.10 to 667 .

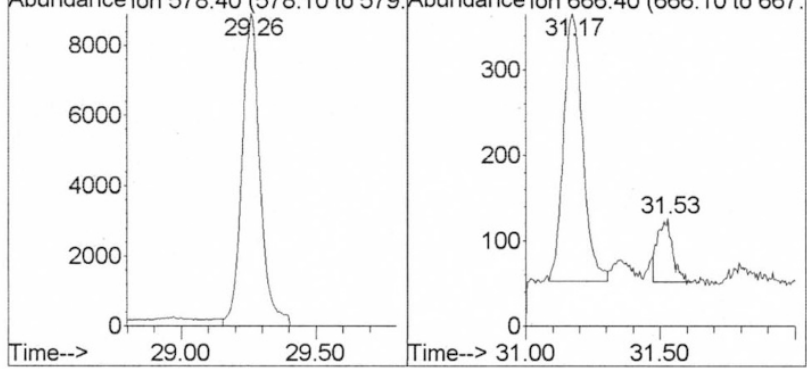

$$
\text { a-Cl b-Cl }
$$
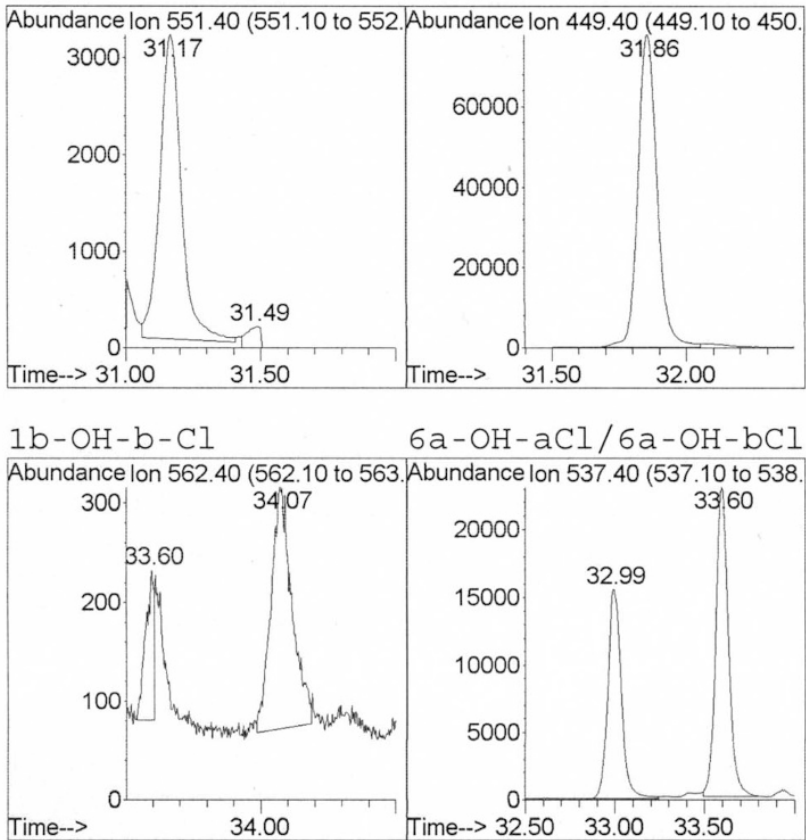

Figure 2. Portions of ion chromatograms of a urinary steroid profile of a premature infant ( $26 \mathrm{wk}$ of gestation; birth weight, $1100 \mathrm{~g}$ ) on d 3 of life. The steroid profile was recorded with the mass spectrometer run in the selected ion monitoring (SIM) mode (Agilent 6890 series GC coupled with an Agilent 5973 mass selective detector). The peaks at typical retention times $\left(\mathrm{t}_{\mathrm{r}}\right)$ represent the following compounds: THE $(\mathrm{m} / \mathrm{z}$ $\left.578.40, \mathrm{t}_{\mathrm{r}} 29.26 \mathrm{~min}\right), 6 \alpha-\mathrm{OH}-\mathrm{THE}\left(\mathrm{m} / \mathrm{z} 666.40, \mathrm{t}_{\mathrm{r}} 31.17 \mathrm{~min}\right), 1 \beta-\mathrm{OH}-\mathrm{THE}(\mathrm{m} / \mathrm{z}$ $\left.666.40, \mathrm{t}_{\mathrm{r}} 31.53 \mathrm{~min}\right), \alpha-\mathrm{CL}\left(\mathrm{m} / \mathrm{z} 551.40, \mathrm{t}_{\mathrm{r}} 31.17 \mathrm{~min}\right), \beta-\mathrm{CL}\left(\mathrm{m} / \mathrm{z} 449.40, \mathrm{t}_{\mathrm{r}} 31.86\right.$ $\mathrm{min}), 1 \beta-\mathrm{OH}-\beta-\mathrm{CL}\left(\mathrm{m} / \mathrm{z} 562.40, \mathrm{t}_{\mathrm{r}} 34.07 \mathrm{~min}\right), 6 \alpha-\mathrm{OH}-\alpha-\mathrm{CL}\left(\mathrm{m} / \mathrm{z} 537.40, \mathrm{t}_{\mathrm{r}} 32.99\right.$ $\mathrm{min})$, and $6 \alpha-\mathrm{OH}-\beta-\mathrm{CL}\left(\mathrm{m} / \mathrm{z} 537.40, \mathrm{t}_{\mathrm{r}} 33.60 \mathrm{~min}\right)$.

Table 1. Evaluation of the urine collection procedure I: recovery of urinary volumes and total urinary glucocorticoid concentrations (sum of glucocorticoid metabolites) after hydraulic compression of small and medium nappies

\begin{tabular}{|c|c|c|c|c|c|}
\hline \multicolumn{2}{|c|}{ Pool urine (control specimens) } & \multicolumn{4}{|c|}{ Urine recovered from nappies } \\
\hline Volume (mL) & $\begin{array}{l}\text { Total glucocorticoids } \\
(\mu \mathrm{g})\end{array}$ & $\begin{array}{l}\text { Total volume } \\
\text { recovered }(\mathrm{mL})\end{array}$ & $\begin{array}{l}\text { Relative volume } \\
\text { recovery }(\%)\end{array}$ & $\begin{array}{l}\text { Total glucocorticoid } \\
\quad \text { content }(\mu \mathrm{g})\end{array}$ & $\begin{array}{c}\text { Relative glucocorticoid } \\
\text { recovery }(\%)\end{array}$ \\
\hline \multicolumn{6}{|c|}{$\begin{array}{l}\text { Small nappies }(n=5 \text { for each } \\
\text { different volume) }\end{array}$} \\
\hline 15 & $79 \pm 1$ & $5.6 \pm 1.6$ & 37 & $82 \pm 4$ & 104 \\
\hline 30 & $158 \pm 2$ & $17.6 \pm 3.1$ & 59 & $167 \pm 9$ & 105 \\
\hline \multicolumn{6}{|c|}{$\begin{array}{c}\text { Medium nappies ( } n=5 \text { for } \\
\text { each different volume) }\end{array}$} \\
\hline 30 & $158 \pm 2$ & $15.8 \pm 1.0$ & 53 & $164 \pm 7$ & 104 \\
\hline 50 & $264 \pm 3$ & $36.4 \pm 2.2$ & 73 & $282 \pm 8$ & 107 \\
\hline 70 & $369 \pm 4$ & $55.2 \pm 2.5$ & 79 & $398 \pm 12$ & 108 \\
\hline
\end{tabular}

To correct for the difference between inoculated and extracted volume, amounts of recovered steroids were calculated by multiplying the concentration of the steroid with the respective inoculated volumes. Data are given as mean \pm SD. 
Preterm infants were placed on a nappy of the appropriate size. Nappies were closed properly to limit evaporation, even when the infant underwent phototherapy. It was shown that phototherapy was associated with slight but significant changes in evaporation (11). The common interval for changing the nappies was $4 \mathrm{~h}$. However, to be able to collect a sufficient volume of urine for steroid analysis in the smallest infants, the nappies were changed every $8 \mathrm{~h}$. Weighing the nappies before and after urine collections allowed exact calculation of 24-h urine output (10). To reduce contamination with meconium or stool to a minimum, a thin gauze was placed between the baby's skin and the surface of the inner side of the nappy, thus, allowing urine to pass through the gauze and, at the same time, withholding meconium or stool, which then could easily be separated from the nappy. Samples from infants with diarrhea were omitted.

Nappies were collected in a plastic bag at room temperature until completion of a 24-h collection period and then stored at $-20^{\circ} \mathrm{C}$. At weekly intervals, nappies were defrosted, folded inside out, and placed in a plastic bag (Melitta, Minden, Germany) before extraction of the urine using a specially constructed hydraulic press applying a maximum of $120 \mathrm{kPa} / \mathrm{cm}^{2}$. The extracted urine from a 24-h urine collection was pooled. After centrifugation, the collected urinary specimens were stored at $-80^{\circ} \mathrm{C}$ until analysis by GC-MS was performed (Fig. 1).

To calculate the 24-h excretion rates of urinary glucocorticoids, the amount of urine that could not be completely squeezed out of the nappy, had to be taken into account. Thus, steroid concentrations were adjusted for the 24-h urine output, which was determined by weighing the nappies.

Laboratory analyses. Urinary steroid profiles were determined using quantitative data produced by GC-MS analysis according to the method of Shackleton and colleagues $(12,13)$. In brief, free and conjugated urinary steroids were extracted by solid phase extraction (Sep-Pak C18 cartridges; Waters, Milford, MA) from a 5-mL aliquot of a 24-h urinary specimen. The conjugates were enzymatically hydrolyzed (type $\mathrm{H}-1$ sulfatase from helix pomatia; SigmaAldrich Chemie GmbH, Taufkirchen bei München, Germany), followed by recovery of the hydrolyzed steroids by a second solid phase extraction step. Known amounts of three internal standards ( $5 \alpha$-androstane- $3 \alpha, 17 \alpha$-diol; stigmasterol; and cholesteryl butyrate) were added to a portion of each extract before formation of methyloxime-trimethylsilyl ethers. The gas chromatograph (6890 series GC; Agilent Technologies GmbH, Böblingen, Germany), housing a OV-1 fused silica column (Optima-1-MS, $25 \mathrm{~m} \times 0.2 \mathrm{~mm}$; film $0.1 \mu \mathrm{m}$; Macherey-Nagel, Düren, Germany) and equipped with an Agilent 7683 series injector, was directly interfaced to a mass selective detector (Agilent $5973 \mathrm{~N}$ MSD) operated in selected ion monitoring mode. Helium was used as carrier gas. The injections took place with the $\mathrm{GC}$ oven at $80^{\circ} \mathrm{C}$ for $2 \mathrm{~min}$; the temperature was gradually increased by $20^{\circ} \mathrm{C} / \mathrm{min}$ up to $190^{\circ} \mathrm{C}(1 \mathrm{~min})$. For separation of steroids, the temperature was increased by $2.5^{\circ} \mathrm{C} / \mathrm{min}$ to $272^{\circ} \mathrm{C}$.

The following $\mathrm{C} 21$ steroids, all cortisol metabolites, were determined by selected ion monitoring: tetrahydrocortisone (THE; $5 \beta$-pregnan- $3 \alpha, 17 \alpha, 21$ triol-11,20-dione; m/z 578); $\alpha$-cortolone ( $\alpha$-CL; $5 \beta$-pregnan- $3 \alpha, 17 \alpha, 20 \alpha, 21$ - tetrol-11-one; $\mathrm{m} / \mathrm{z} 551$ ); $\beta$-cortolone ( $\beta$-CL; $5 \beta$-pregnan- $3 \alpha, 17 \alpha, 20 \beta$, 21-tetrol-11-one; $\mathrm{m} / \mathrm{z} 449) ; 6 \alpha$-OH-tetrahydrocortisone $(6 \alpha$-OH-THE; $5 \beta$ pregnan-3 $\alpha, 6 \alpha, 17 \alpha, 21$-tetrol-11,20-dione; $\mathrm{m} / \mathrm{z} 666) ; 1 \beta$-OH-tetrahydrocortisone ( $1 \beta$-OH-THE; $5 \beta$-pregnan- $1 \beta, 3 \alpha, 17 \alpha, 21$-tretrol-11,20-dione; $\mathrm{m} / \mathrm{z} 666$ ); $6 \alpha$-OH- $\alpha$-cortolone $(6 \alpha-\mathrm{OH}-\alpha$-CL; $5 \beta$-pregnan-3 $\alpha, 6 \alpha, 17 \alpha, 20 \alpha, 21$-pentol-11one; $\mathrm{m} / \mathrm{z}$ 537); $6 \alpha-\mathrm{OH}-\beta$-cortolone $(6 \alpha-\mathrm{OH}-\beta-\mathrm{CL} ; \quad 5 \beta$-pregnan$3 \alpha, 6 \alpha, 17 \alpha, 20 \beta, 21$-pentol-11-one; m/z 537); $1 \beta$-OH- $\beta$-cortolone $(1 \beta$-OH- $\beta$-CL; $5 \beta$-pregnan- $1 \beta, 3 \alpha, 17 \alpha, 20 \beta, 21$-pentol-11-one; $\mathrm{m} / \mathrm{z} 562$ ); tetrahydrocortisol (THF; $5 \beta$-pregnan-3 $\alpha, 11 \beta, 17 \alpha, 21$-tetrol-20-one; $\mathrm{m} / \mathrm{z} 652$ ); allotetrahydrocortisol ( $5 \alpha$ pregnan- $3 \alpha, 11 \beta, 17 \alpha, 21$-tetrol-20-one; $\mathrm{m} / \mathrm{z}$ 652); $\alpha$-cortol $(\alpha-\mathrm{C} ; 5 \beta$ pregnan- $3 \alpha, 11 \beta, 17 \alpha, 20 \alpha, 21$-pentol; $\mathrm{m} / \mathrm{z} 523$ ); $\beta$-cortol ( $\beta$-C; $5 \beta$-pregnan$3 \alpha, 11 \beta, 17 \alpha, 20 \beta, 21$-pentol; m/z 523); cortisol (F; 4-pregnene- $11 \beta, 17 \alpha, 21$ triol-3,20-dione; $\mathrm{m} / \mathrm{z} 605$ ); and $6 \beta$-OH-cortisol (6 $\beta$-OH-F; 4-pregnene$6 \beta, 11 \beta, 17 \alpha, 21$-tetrol-3,20-dione; $\mathrm{m} / \mathrm{z} 693$ ). In addition to these target ions, a second ion (qualifier ion) was monitored for each analyte to ensure specificity. Calibration plots showed excellent linearity $\left(r^{2}=0.982\right.$ 1.000). To assess overall cortisol secretion, the 14 major urinary glucocorticoid metabolites were quantified (peak area integration) and summed. As usually done with GC-MS steroid analysis, single measurements were performed for each urine sample. Intra-assay precision $(n=8)$ varied between $1.3 \%$ (for $6 \alpha-\mathrm{OH}-\beta-\mathrm{CL}$ ) and $7.0 \%$ (for $1 \beta-\mathrm{OH}-\beta-\mathrm{CL}$ ), and interassay precision $(n=6)$ varied between $0.5 \%$ (for THE) and $5.3 \%$ (for $1 \beta-\mathrm{OH}-\beta$ $\mathrm{CL}$ ). Creatinine was measured by the Jaffé method. Daily urinary excretion rates of glucocorticoids were corrected for body weight and per micromole creatinine.

Evaluation of urine collection procedure. Pooled neonatal urine was used for testing our urine collection procedure. To simulate a normal 24-h collection procedure, the nappies were inoculated with aliquots of pooled urine and stored for $36 \mathrm{~h}$ in plastic bags at room temperature; small nappies were inoculated with aliquots of 15,30 , and $45 \mathrm{~mL}$ of urine and medium nappies with 30,50 , and $70 \mathrm{~mL}$, respectively. Each nappy was weighed before and after inoculation with urine. After incubation, nappies were stored at $-20^{\circ} \mathrm{C}$ until urine was extracted as mentioned above.

Determination of steroid excretion rates in preterm infants. Nine preterm infants (five females) with a median gestational age of $28.7 \mathrm{wk}$ (range, $25.0-$ 30.9 ) and a median birth weight of $1080 \mathrm{~g}$ (range, 640-1690) were investigated. Six of nine infants were delivered by cesarean section. All infants were classified as being healthy according to recently described criteria (14). They had no signs of infection and did not receive treatment with surfactant or inotropes. A postnatal steroid therapy was an exclusion criterion. All mothers received a complete course of prenatal betamethasone therapy. Twenty-fourhour urine collections were made on d 1,2,3, and 5 of life and at weekly intervals thereafter up to the age of $4 \mathrm{wk}$.

Additionally, steroid excretion rates of five preterm infants with arterial hypotension as a potential sign of adrenal insufficiency were determined. The Score for Neonatal Acute Physiology (SNAP) served as an indicator of the severity of illness (15).

Table 2. Evaluation of urine collection procedure II: relative recovery of individual urinary glucocorticoid metabolites after extraction from pure cellulose nappies

\begin{tabular}{|c|c|c|c|c|c|c|}
\hline & \multicolumn{3}{|c|}{ Small nappies, volume incubated $(\mathrm{mL})$} & \multicolumn{3}{|c|}{ Medium nappies, volume incubated (mL) } \\
\hline & $15(n=5)$ & $30(n=5)$ & $45(n=5)$ & $30(n=5)$ & $50(n=5)$ & $70(n=5)$ \\
\hline \multicolumn{7}{|c|}{ Recovery of 11-hydroxy-metabolites (\%) } \\
\hline $6 \beta-\mathrm{OH}-\mathrm{F}$ & 59 & 70 & 90 & 66 & 70 & 93 \\
\hline THF & 112 & 112 & 112 & 101 & 99 & 101 \\
\hline$\alpha \mathrm{THF}$ & 115 & 117 & 119 & 100 & 102 & 104 \\
\hline$\beta-\mathrm{C}$ & 104 & 101 & 109 & 96 & 101 & 102 \\
\hline \multicolumn{7}{|c|}{ Recovery of 11-keto-metabolites (\%) } \\
\hline THE & 101 & 100 & 105 & 97 & 99 & 101 \\
\hline $1 \beta-\mathrm{OH}-\mathrm{THE}$ & 108 & 109 & 121 & 109 & 107 & 108 \\
\hline $6 \alpha-\mathrm{OH}-\mathrm{THE}$ & 115 & 116 & 118 & 111 & 111 & 112 \\
\hline$\alpha-\mathrm{CL}$ & 110 & 112 & 116 & 103 & 115 & 111 \\
\hline $6 \alpha-\mathrm{OH}-\alpha-\mathrm{CL}$ & 108 & 109 & 110 & 107 & 111 & 112 \\
\hline
\end{tabular}

Various sizes of nappies were employed and different amounts of aliquots of pool urine were used for incubation. To correct for the difference between inoculated and extracted volume, amounts of recovered steroids were calculated by multiplying the concentration of the steroid with the respective inoculated volumes. Then, the recovery rate of the individual steroid is presented as percentage of the inoculated amount of the metabolite. 
The parents gave written informed consent. The study was approved by the local ethics committee.

Statistics. All data were analyzed in the Institute of Medical Statistics using the SAS V8 statistical package (SAS Institute Inc., Cary, NC). Intragroup changes in excretion rates of urinary glucocorticoids were compared over time by paired Wilcoxon test.

\section{RESULTS}

Evaluation of the urine collection procedure. Urinary volumes and amounts of total glucocorticoid metabolites recovered after hydraulic compression of nappies are given in Table 1. The amounts of total glucocorticoid metabolites in native urine were compared with those determined in urine recovered from nappies. For the correction of the difference between inoculated and extracted volume, amounts of recovered steroids were calculated by multiplying the concentration of the steroid with the respective inoculated volumes.

Fourteen urinary glucocorticoid metabolites were identified by GC-MS. Portions of a typical urinary steroid profile (selected ion monitoring data) of a preterm infant of $25 \mathrm{wk}$ gestational age are shown in Figure 2.

Relative recovery rates of individual glucocorticoid metabolites after extraction from nappies are given in Table 2. Recovery rates were excellent with a mean (SD) of $105 \%$ $(12.3 \%)$. No relevant influences were noted with regard to nappy size and urine volume.

Determination of steroid excretion rates in preterm infants. Results of urinary excretion rates of glucocorticoids in healthy preterm infants as a function of postnatal age are shown in Figure 3. When calculated per kilogram body weight, the median urinary excretion rates of glucocorticoids increased during the first $5 \mathrm{~d}$ of life $(p<0.015$; Fig. $3 A)$. Thereafter, there was no change in urinary excretion rates of glucocorticoids.

When calculated per micromole creatinine, the progression of the curve was smoothed and only a slight, nonsignificant increase of the urinary excretion rates of glucocorticoids from $\mathrm{d} 1$ to $\mathrm{d} 3$ was noted (Fig. 3B). The following urinary excretion rates of glucocorticoids corrected for creatinine declined at $\mathrm{d} 3$ from $5.3 \mu \mathrm{g} / \mathrm{kg} / \mathrm{d}$ per micromole creatinine to $2.8 \mu \mathrm{g} / \mathrm{kg} / \mathrm{d}$ per micromole creatinine at wk $4(p<0.02)$.

When calculated per square meter of body surface area, the median urinary excretion rates of glucocorticoids were 5.1, $4.2,4.1$, and $3.7 \mathrm{mg} / \mathrm{m}^{2} / \mathrm{d}$ at $\mathrm{d} 5$ and $\mathrm{wk} 2,3$, and 4 , respectively.

Table 3 shows the excretion rates of individual glucocorticoid metabolites to describe their contribution to total glucocorticoid excretion. 11-keto-metabolites (cortisone metabolites) represented $80-96 \%$ of the total glucocorticoids excreted.

Finally, the urinary excretion rates of glucocorticoids were determined in five preterm infants with arterial hypotension requiring treatment with catecholamines. The severity of illness was high during the first week of life, as indicated by high SNAP in all five infants (Fig. $4 A$ ). In two of the five infants with hypotension and severe illness, the urinary excretion rates of glucocorticoids did not increase (Fig. 4B). Table 4 shows the clinical characteristics of these infants.
(A)

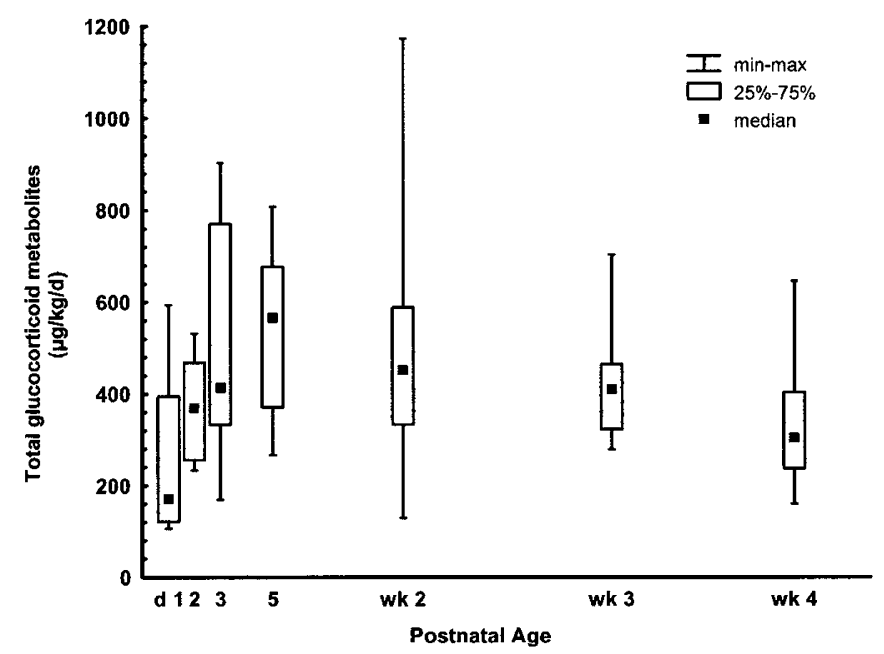

(B)

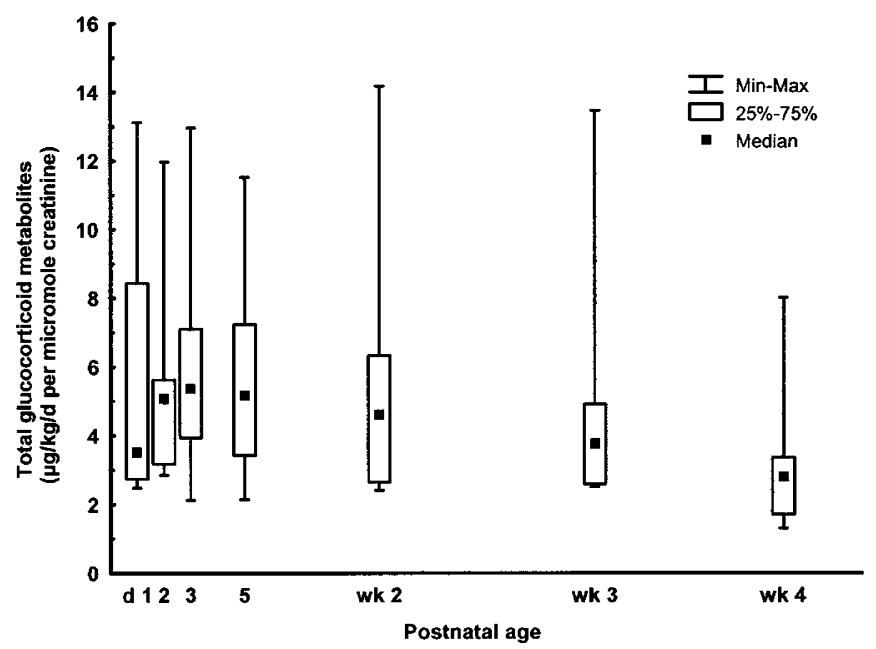

Figure 3. (A) Changes in urinary excretion rates of total glucocorticoid metabolites in healthy preterm infants $(n=9)$ as a function of postnatal age. The increase during the first $5 \mathrm{~d}$ of life was significant $(p<0.015)$. (B) Excretion rates corrected per micromole creatinine to take immediately postnatal changes of renal function into account. There was a significant decline from the $\mathrm{d} 3$ to wk $4(p<0.02)$.

\section{DISCUSSION}

When trying to assess cortisol production by measuring urinary excretion rates of glucocorticoids, a reliable method ensuring complete collection of urine is of crucial importance. The use of adhesive plastic collection bags on the perineum is problematic for several reasons. First, removing the bag from the perineum can result in abrasions and tears in the extremely vulnerable skin of the premature infant. Secondly, especially in female neonates, it is not easy and always reliable to achieve a complete urine collection, due to leakage of the system. Alternatively, a bed can be used, wherein the baby is placed on a nylon sheet through which urine can pass and be channeled to a collection point $(16,17)$. The disadvantages of this system include skin care in immobilized, extremely ill infants, and impracticality in more mobile older infants. Bladder catheterization is invasive and not acceptable for study reasons. 
Table 3. Twenty-four-hour urinary excretion rates of individual glucocorticoid metabolites $(\mu \mathrm{g} / \mathrm{kg} / \mathrm{d})$ in healthy preterm infants $(\mathrm{n}=9)$

\begin{tabular}{|c|c|c|c|c|c|c|c|}
\hline & d 1 & d 2 & d 3 & d 5 & wk 2 & wk 3 & wk 4 \\
\hline \multicolumn{8}{|c|}{ 11-hydroxy-metabolites } \\
\hline $\mathrm{F}$ & $10.6(5.1-53.9)$ & $10(6.7-102.8)$ & $12.4(4.5-192.2)$ & $9.9(4.5-47.4)$ & $5.8(0-19.8)$ & $5.5(2.3-12.3)$ & $4.8(4-10.1)$ \\
\hline $6 \beta-\mathrm{OH}-\mathrm{F}$ & $8.3(0-61.5)$ & $17.8(0-47.5)$ & $18.3(0-65.6)$ & $19.7(0-167.2)$ & $12.4(0-99.4)$ & $11.4(0-16.3)$ & $6.7(0-15.2)$ \\
\hline THF & $1.7(0-11.8)$ & $3.2(0-7.9)$ & $2.2(0-6.4)$ & $0(0-7.2)$ & $3(0-7.9)$ & $2.3(0-3.5)$ & $2.5(0-6.4)$ \\
\hline$\alpha \mathrm{THF}$ & $0(0-4.5)$ & $1.3(0-5.3)$ & $0(0-5.7)$ & $0(0-6.7)$ & $0(0-3.4)$ & $0(0-2.3)$ & $0(0-9.1)$ \\
\hline$\alpha-\mathrm{C}$ & $0(0-1.3)$ & $0(0-2.1)$ & $0(0-1.4)$ & $0(0-1.3)$ & $0(0-1.5)$ & $0(0-1.3)$ & $0(0-0.4)$ \\
\hline$\beta-\mathrm{C}$ & $0.2(0-6.1)$ & $0(0-5.3)$ & $0(0-9.8)$ & $0(0-5.1)$ & 0 & 0 & $0(0-1.8)$ \\
\hline \multicolumn{8}{|c|}{ 11-keto-metabolites } \\
\hline THE & $25.4(13.2-75.8)$ & $36.8(18.1-62.3)$ & $37.5(26.6-73.9)$ & $52.6(15.7-110.8)$ & $50.2(19.4-118.3)$ & $66.2(47-107.6)$ & $51.6(33.2-174.1)$ \\
\hline $1 \beta$-OH-THE & $0.3(0-5.1)$ & $0.9(0-3.4)$ & $1.1(0-4.3)$ & $2.4(0-4.3)$ & $2.2(1.1-5.3)$ & $2(1.1-4.5)$ & $2.1(1.1-4.2)$ \\
\hline $6 \alpha-\mathrm{OH}-\mathrm{THE}$ & $13.2(3.5-43.3)$ & $14.1(3-69.9)$ & $17.2(2.7-60.2)$ & $36(5.8-59.9)$ & $60(17.4-107.7)$ & $52.6(24-138)$ & $47.1(25.3-150.1)$ \\
\hline$\alpha-\mathrm{CL}$ & $20.4(0-48.2)$ & $19.9(0-33.7)$ & $18.7(0-64.3)$ & $11.5(4.9-36.4)$ & $6.5(3.6-17.6)$ & $3.5(0-6.9)$ & $3.4(0-8)$ \\
\hline $6 \alpha-\mathrm{OH}-\alpha-\mathrm{CL}$ & $21.6(9.7-119.9)$ & $42.6(13.2-134.3)$ & $43.1(7.9-248.2)$ & $44.6(16.3-188.8)$ & $32(7.9-160.6)$ & 35.7 (21.3-95.2) & $30.5(11.8-57.2)$ \\
\hline$\beta-C L$ & $6.5(1.8-90.8)$ & $8.3(3.5-118.4)$ & $10.6(2.3-167)$ & $14.7(6-144.9)$ & $9.5(2-37.6)$ & $13.5(7.2-22.2)$ & $15.8(3.2-31.9)$ \\
\hline $1 \beta-\mathrm{OH}-\beta-\mathrm{CL}$ & $0.8(0-3.8)$ & $2.2(1.5-5.3)$ & $4.5(1.6-5.3)$ & $4.3(0-6.9)$ & $6.0(0-24.5)$ & $5.9(0-10.2)$ & $4.4(0-8.2)$ \\
\hline $6 \alpha-\mathrm{OH}-\beta-\mathrm{CL}$ & $74.9(27.6-250.2)$ & $131.7(108.1-196.2)$ & $224(75.6-307.4)$ & $230.6(114.8-436)$ & $258.7(69.3-623.1)$ & $232.1(125.9-326.3)$ & $122.4(71.6-211.9)$ \\
\hline
\end{tabular}

Data are given as median (minimum-maximum). Individual steroids were quantified by GC-MS in a pooled 24-h urine sample and excretion rates were calculated by adjusting steroid concentration to the 24-h urine output, which was determined by weighing the nappies of a 24-h collection period.

In contrast, collecting urine samples from compressible nappies, taking care to minimize evaporation (11) and correcting for losses by weighing is a suitable alternative for measuring accurately 24-h urine output and determining several constituents of urine $(9,10)$. This method does not interfere with the nursing care and is completely noninvasive and nonstressful. A nonstressful approach is necessary when assessing the function of the permanent adrenal zone, as it has been shown in healthy term infants that plasma cortisol rose up to 11-fold half an hour after a simple venous puncture (18). Furthermore, this method allows urine collection over long periods of time, making longitudinal studies possible for delineation of the change from the neonatal to the adult pattern of cortisol metabolism.

Evaluation of our urine collection procedure showed that application of a hydraulic press allowed sufficient recovery, even when nappies were incubated with small volumes of urine (Table 1). This is of particular importance, especially during the first days of life of the extremely low birth weight infant when urine output is low. The amounts of steroids determined in the urinary specimens recovered after hydraulic pressing of nappies reveal that no relevant bacterial decomposition or absorption of steroids occurs in the filling material of the nappies used. In fact, we observed a negligible "concentration effect" (Table 1), explaining recovery rates slightly more than $100 \%$, which perhaps is due to evaporation or absorption of water by the nappy. We conclude from the high recovery rate of the individual steroids that hardly any absorption or degradation of steroids occurred in case when the nappies were left at room temperature for $36 \mathrm{~h}$ (Table 2).

The nappies used in this study were composed of pure cellulose, whereas the commonly used ultra-absorbent types of nappies were unsuitable for squeezing, because extracted samples always contained the gel-like material of the nappy. Our results demonstrate that glucocorticoid metabolites deriving from the adrenal permanent zone can be identified and quantified by GC-MS from urine collection using disposable nappies with a high recovery rate.

Nonselective multicomponent methods such as gas chromatography or GC-MS are required for profiling steroids in complex steroids mixtures like neonatal urine. The use of
GC-MS permits the highest specificity due to its capacity for providing structural information of the analytes. Urinary steroid profiling by GC-MS is a nonselective procedure of highest diagnostic potential concerning delineation of disorders of human steroid metabolism (19). The high specificity of our GC-MS method can be assessed by the clear shapes of the chromatographic peaks (Fig. 2). In contrast to studies in which quantification of neonatal urinary glucocorticoids relied on gas chromatography, determination by GC-MS and selected ion monitoring did not require separation of steroid sulphates from the free and glucuronide conjugates by chromatography with Sephadex LH-20 columns, a time-consuming, laborious, and expensive preparative step (13). The panel of our analytes comprised all major neonatal neutral cortisol metabolites that were either excreted free or as glucuronides, carrying additional hydroxyl groups at positions $1 \beta$ and $6 \alpha$. We furthermore included all major representative metabolites of the adult pattern of cortisol catabolism. Unlike studies based on quantitative gas chromatography (20), we were able to further determine 11-hydroxy-steroids such as THF and $5 \alpha$-THF, although in minor concentrations, in preterm infants after birth.

In our cohort of healthy preterm infants, the median urinary excretion rates of glucocorticoids tripled during the first $5 \mathrm{~d}$ of life. This may be explained by the increase in glomerular filtration rates directly after birth. Because the immediate postnatal period is of great interest regarding adrenal function in the premature infant, renal function has to be taken into account. Therefore, glucocorticoid excretion rates were corrected for creatinine values. It has already been demonstrated that the determination of creatinine in urinary samples from extracted nappies is reliable and accurate $(9,10)$. Creatinine excretion rates in our population were in the previously reported range for premature infants (21). In our case, excretion rates corrected for creatinine increased only by $50 \%$ during the first $5 \mathrm{~d}$ of life, and thus were not significant. We speculate that glucocorticoid excretion rates corrected for creatinine better reflect adrenal function in the immediate postnatal period of the premature infant.

The median excretion rates of glucocorticoid metabolites in our infants ranged between 170 and $566 \mu \mathrm{g} / \mathrm{kg} / \mathrm{d}$ and were 4 to 

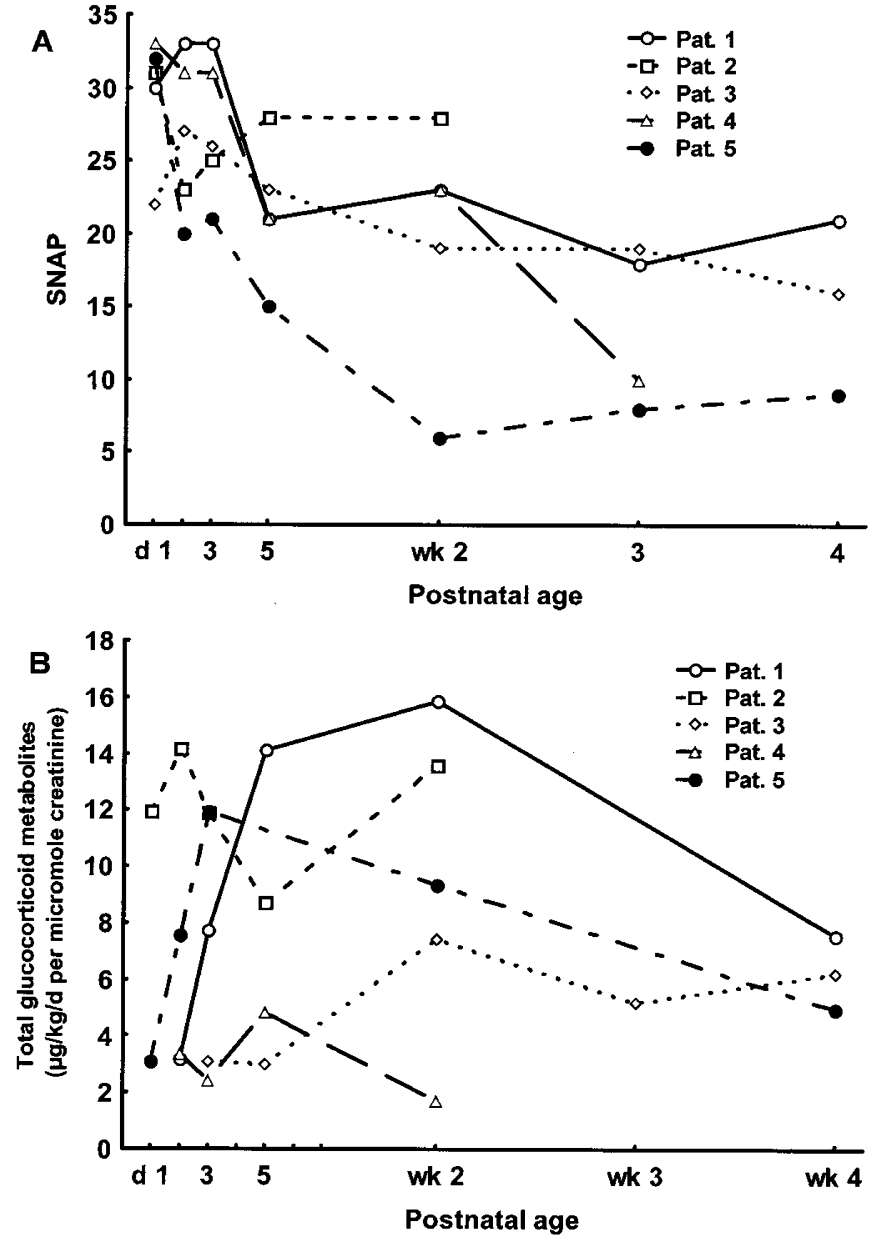

Figure 4. Severity of illness measured by the Score for Neonatal Acute Physiology (SNAP) $(A)$ and urinary excretion rates of glucocorticoids as a function of postnatal age in 5 preterm infants with arterial hypotension requiring treatment with catecholamines $(B)$. Excretion rates were corrected per micromole creatinine.

6 times higher than those reported by Midgley et al. (20). It has been shown that determination of total glucocorticoid metabolites in 24-h urinary specimens reflects $75 \%$ of cortisol production rates in adults (5). It has also been convincingly shown that the urinary excretion rate of free cortisol does not correlate with cortisol production rate $(22,23)$.

Cortisol production rates were reported for moderately premature infants $\left(6.6-8.8 \mathrm{mg} / \mathrm{m}^{2} / \mathrm{d}\right)$ using deconvolution analysis in plasma (24) and for older children $\left(6.8 \pm 1.9 \mathrm{mg} / \mathrm{m}^{2} / \mathrm{d}\right)$ (23) or adults $\left(7.7-11.4 \mathrm{mg} / \mathrm{m}^{2} / \mathrm{d}\right)$ (5) using a stable isotope dilution technique. The median urinary excretion rates of glucocorticoids in our infants reached up to $70 \%$ of these reported cortisol production rates.

Using our method in ill preterm infants, low cortisol production was detected in two of five infants with arterial hypotension requiring treatment with catecholamines. Hypotension in these two male neonates might be a symptom of adrenal insufficiency. In contrast, there was an increase in cortisol production in the three remaining female infants during severe illness. The number of preterm infants investigated in our study was too small to draw any conclusions regarding gender differences in cortisol production in preterm infants. These preliminary data warrant further evaluation in a greater number of infants, because several other factors might influence the adrenal response like gestational age, administration of prenatal steroids, mode of birth, labor, and the nature of neonatal disease. However, our findings indicate that adrenal insufficiency may be not a unique finding in the group of ill preterm infants and steroid treatment may require an individual approach.

In conclusion, 24-h urine collection using disposable nappies in combination with GC-MS steroid profiling proved to be a reliable, noninvasive, and nonstressful procedure in premature infants. We suggest its application as a tool to assess cortisol production and metabolism in these babies.

Acknowledgments. The authors thank Professor Dr. F. Manz (Research Institute of Child Nutrition, Dortmund, Germany), who provided the hydraulic press; Professor Dr. J Homoki (Department of Pediatrics, University of Ulm, Germany) for providing reference steroids; Dr. M. Lazaro for editing the manuscript; and Procter \& Gamble for providing the mediumsized nappies.

Table 4. Clinical characteristics of five preterm infants with arterial hypotension as a potential sign of adrenal insufficiency

\begin{tabular}{|c|c|c|c|c|c|}
\hline & \multicolumn{5}{|c|}{ Patient no. } \\
\hline & 1 & 2 & 3 & 4 & 5 \\
\hline Gestational age (wk) & 27.6 & 25.1 & 25.9 & 25.9 & 28.3 \\
\hline Gender, male & & & $\mathrm{x}$ & $\mathrm{x}$ & \\
\hline Prenatal steroids (complete course) & & & & & $\mathrm{x}$ \\
\hline Prenatal steroids (incomplete course) & & $\mathrm{x}$ & $\mathrm{x}$ & $\mathrm{x}$ & \\
\hline Apgar scores at $5 \mathrm{~min}$ & 8 & 7 & 8 & 5 & 9 \\
\hline RDS treated with surfactant & $\mathrm{x}$ & $\mathrm{x}$ & $\mathrm{x}$ & $\mathrm{x}$ & $\mathrm{x}$ \\
\hline PDA requiring treatment & $\mathrm{x}$ & $\mathrm{x}$ & & & $\mathrm{x}$ \\
\hline Intraventricular hemorrhage $>\mathrm{II}^{\circ}$ & $\mathrm{x}$ & $\mathrm{x}$ & & $\mathrm{x}$ & $\mathrm{x}$ \\
\hline NEC & $\mathrm{x}$ & & $\mathrm{x}$ & & \\
\hline Infection at birth & $\mathrm{x}$ & & $\mathrm{x}$ & $\mathrm{x}$ & $\mathrm{x}$ \\
\hline
\end{tabular}

RDS, respiratory distress syndrome; PDA, patent ductus arteriosus; NEC, necrotizing enterocolitis. 


\section{REFERENCES}

1. Heckmann M, Wudy SA, Haack D, Pohlandt F 2000 Serum cortisol concentrations in ill preterm infants less than 30 weeks gestational age. Acta Paediatr 89:1098-1103

2. Huysman MW, Hokken-Koelega AC, De Ridder MA, Sauer PJ 2000 Adrenal function in sick very preterm infants. Pediatr Res 48:629-633

3. Scott SM, Watterberg KL 1995 Effect of gestational age, postnatal age, and illness on plasma cortisol concentrations in premature infants. Pediatr Res 37:112-116

4. Mesiano S, Jaffe RB 1997 Developmental and functional biology of the primate fetal adrenal cortex. Endocr Rev 18:378-403

5. Kraan GP, Dullaart RP, Pratt JJ, Wolthers BG, Drayer NM, De Bruin R 1998 The daily cortisol production reinvestigated in healthy men. The serum and urinary cortisol production rates are not significantly different. J Clin Endocrinol Metab $83: 1247-1252$

6. Zumoff B, Fukushima DK, Hellman L 1974 Intercomparison of four methods for measuring cortisol production. J Clin Endocrinol Metab 38:169-175

7. Fujitaka M, Jinno K, Sakura N, Takata K, Yamasaki T, Inada J, Sakano T, Horino N, Kidani K, Ueda K 1997 Serum concentrations of cortisone and cortisol in premature infants. Metabolism 46:518-521

8. Nahoul K, Daffos F, Forestier F, Chartier M, Scholler R 1988 Plasma corticosteroid patterns in the fetus. J Steroid Biochem 29:635-640

9. Ahmad T, Vickers D, Campbell S, Coulthard MG, Pedler S 1991 Urine collection from disposable nappies. Lancet 338:674-676

10. Roberts SB, Lucas A 1985 Measurement of urinary constituents and output using disposable napkins. Arch Dis Child 60:1021-1024

11. Gouyon JB, Sonveau N, d'Athis P, Chaillot B 1994 Accuracy of urine output measurement with regular disposable nappies. Pediatr Nephrol 8:88-90

12. Caulfield MP, Lynn T, Gottschalk ME, Jones KL, Taylor NF, Malunowicz EM, Shackleton CH, Reitz RE, Fisher DA 2002 The diagnosis of congenital adrenal hyperplasia in the newborn by gas chromatography/mass spectrometry analysis of random urine specimens. J Clin Endocrinol Metab 87:3682-3690
13. Honour JW, Kent J, Shackleton CH 1983 Improved recoveries in the extraction of steroids from neonatal urine. Clin Chim Acta 129:229-232

14. Heckmann M, Wudy SA, Haack D, Pohlandt F 1999 Reference range for serum cortisol in well preterm infants. Arch Dis Child Fetal Neonatal Ed 81:F171F174

15. Richardson DK, Gray JE, McCormick MC, Workman K, Goldmann DA 1993 Score for Neonatal Acute Physiology: a physiologic severity index for neonatal intensive care. Pediatrics 91:617-623

16. Coulthard MG 1982 Device for continuous urine collection in the newborn. Arch Dis Child 57:322

17. Lund RJ, Valman HB, Platt A 1981 Device for continuous urine collection in the newborn. Arch Dis Child 56:880-882

18. Mantagos S, Koulouris A, Vagenakis A 1991 A simple stress test for the evaluation of hypothalamic-pituitary-adrenal axis during the first 6 months of life. J Clin Endocrinol Metab 72:214-216

19. Wudy SA, Homoki J, Teller WM 2001 Clinical steroid analysis by gas chromatography-mass spectrometry. In: Niessen WMA (ed) Current Practice of Gas Chromatography-Mass Spectrometry. Marcel Dekker, New York, pp 309-339

20. Midgley PC, Holownia P, Smith J, Moore M, Russell K, Oates N, Shaw JC, Honour JW 2001 Plasma cortisol, cortisone and urinary glucocorticoid metabolites in preterm infants. Biol Neonate 79:79-86

21. Wilkins BH 1992 Renal function in sick very low birthweight infants: 2. Urea and creatinine excretion. Arch Dis Child 67:1146-1153

22. Kerrigan JR, Veldhuis JD, Leyo SA, Iranmanesh A, Rogol AD 1993 Estimation of daily cortisol production and clearance rates in normal pubertal males by deconvolution analysis. J Clin Endocrinol Metab 76:1505-1510

23. Linder BL, Esteban NV, Yergey AL, Winterer JC, Loriaux DL, Cassorla F 1990 Cortisol production rate in childhood and adolescence. J Pediatr 117:892-896

24. Metzger DL, Wright NM, Veldhuis JD, Rogol AD, Kerrigan JR 1993 Characterization of pulsatile secretion and clearance of plasma cortisol in premature and term neonates using deconvolution analysis. J Clin Endocrinol Metab 77:458-463 